\title{
Measuring the impact of a mathematics intervention on student mathematics self-efficacy: Development and application of revised measurement tool
}

\section{Dr. Anthony Bourne, Wright State University}

Dr. Bourne is the Director of Enrollment Management at Wright State University and completed his $\mathrm{PhD}$ in Engineering at Wright State. He holds a BA in Economics and MPA. His research focus is in engineering education and student success measures in engineering curriculum.

\section{Prof. Nathan W. Klingbeil, Wright State University}

Nathan Klingbeil is a Professor of Mechanical Engineering and Dean of the College of Engineering and Computer Science at Wright State University. He is the lead PI for Wright State's National Model for Engineering Mathematics Education, which has been supported by both NSF STEP Type 1 and CCLI Phase 3 awards. He has received numerous awards for his work in engineering education, and was named the 2005 Ohio Professor of the Year by the Carnegie Foundation for the Advancement of Teaching and Council for Advancement and Support of Education (CASE).

Dr. Frank W. Ciarallo, Wright State University 
Measuring the impact of a mathematics intervention on student mathematics self-efficacy: Development and application of revised measurement tool 
Research into the effectiveness of a mathematics intervention course for first year engineering students revealed anomalous results in relation to student persistence. While previous studies of performance of college engineering students showed that ACT Math scores were highly linearly predictive of student persistence outcomes, the study in question did not show similar results. The study revealed an interaction between ACT Math and high school GPA for students that completed the course. The results showed an inverse relationship between ACT Math and persistence in college engineering when high school GPA crossed effects were included. It was hypothesized that a change in mathematics self-efficacy may play a role in the improvement in graduation rates of students with above average high school GPAs, but below average ACT Math scores, subsequently named Support Seekers. Support Seekers showed improved graduation rates disproportionately higher than other groups. A new mathematics self-efficacy measurement tool was needed to determine if a change in mathematics self-efficacy occurred as previous iterations of the Mathematics Self-Efficacy Scale (MSES) and Mathematics SelfEfficacy Scale Revised (MSES-R) were not adequate in showing a change in self-efficacy over time. This paper reviews the development of the newly revised mathematics self-efficacy tool, the effectiveness of the tool and the outcome of the effectiveness of the mathematics intervention course on improving mathematics self-efficacy of freshmen engineering students.

\section{Introduction}

The ability and usefulness of determining students' mathematics self-efficacy has been well documented (Lent 1991, 2008). To date, this process has been used to determine student mathematics efficacy in a global sense and has provided a snapshot in time of what perception students have of their own mathematics ability. This has a limitation on the ability to measure the change in efficacy a student may experience over time, however.

It is to be expected that students' mathematics ability will improve, if not their belief in this ability, and therefore the content of a self-efficacy measure must match the level of the student at the time in which they take the survey. One can imagine that the self-efficacy measure for a junior high school student would have much different content than that of a college freshman; that difference is fairly obvious.

This study attempts to develop a self-efficacy measurement method that may be used to determine if a change in self-efficacy occurs over one semester while students take a mathematics intervention course (EGR1010) which covers topics ranging from trigonometry through differential equations. The course includes lecture, lab, and recitation sections and is taught using engineering context for the mathematics material. The ability to measure this change may provide greater understanding of the success of the course which has been discussed in previous papers. (Klingbeil 2012) The assumption is that self-efficacy may play a role in helping students graduate with engineering degrees even while not having traditionally strong backgrounds in mathematics. 
The goals of the study are as follows:

A. Develop a survey mechanism to accurately record student efficacy in mathematics and engineering for pre and post course use to measure if a change in self-efficacy occurs.

B. Validate the survey tool from the data collected to determine if the survey components provide adequate feedback for assessment of question levels and consistency among survey results.

C. Analyze the data to determine the nature of any change from the pre and post survey represented in the student responses.

D. Align any conclusions with those of the ACT Engage survey to further explain the previous findings regarding the success of EGR1010, especially for the Support Seeker group.

\section{Survey development}

The efficacy survey utilized in this study is a refinement of the Mathematics SelfEfficacy Scale Revised (MSES-R). MSES-R does not provide sufficient engineering context, and is not useful as a tool to measure change in efficacy (Barker 2010, Burnham 2011). The refined instrument was not primarily intended to provide an absolute measure of a student's efficacy. The goal was a tool that can be utilized to compare pre-course and post-course results or compare different students in one cohort.

The following analysis expands the insights from a previous study whereby the efficacy measure was further developed through an understanding of the student group based on mathematics-specific efficacy (Bourne, 2014). This study developed the Academic Performance Commitment Matrix (APCM) which shows how student perceptions taken from the ACT Engage survey may be used to demonstrate success in academics when viewed through the cross section of ACT Mathematics score and high school GPA when dividing students into quadrants of above and below average means of each measure.

Because self-efficacy is best tested as a subject-specific measure (Lent, 2008) determining a mathematics content for engineering students is a challenging proposition. Given the varied nature of different engineering disciplines, however, mathematics content present in all engineering disciplines provides a unifying basis to generally measure efficacy in engineering students. Where previous attempts at measuring the effectiveness of EGR1010 through mathematics efficacy utilized non-context oriented questions (Barker 2010, Burnham 2011), the revised survey developed for this portion of the research provides a tool designed around both mathematics content and engineering context.

Two survey instruments were used, one in the first week of the EGR1010 course in Fall 2013 (the pre-course survey), and one in the final week of the course (the post-course survey). The pre-course survey, shown in Appendix A, has three levels of questions with increasing difficulty, labeled ESY, MED, and HRD. Each difficulty level has six questions. In the postcourse survey, shown in Appendix B, there are also three levels of questions with increasing difficulty. Identical questions from the pre-course survey were used for levels MED and HRD in the post-course survey, and a new level ADV was added. Students were asked to rate their 
confidence (on a Likert scale of 1 to 5) in their ability to solve each question given they were to take a course covering the type of question being asked.

ESY questions represent mathematics topics the students should have covered in previous courses as a prerequisite to EGR1010. Topics in trigonometry, basic physics and algebra II were used.

MED questions represent mathematics topics taught in the first few weeks of EGR1010. Students may or may not have seen these concepts in earlier coursework, but will certainly cover them by the end of the EGR1010 course.

HRD questions represent information that students most likely have not seen in earlier coursework before EGR1010. This includes Calculus I and II concepts as well as those from introductory engineering courses like Statics and Circuits I.

ADV questions represent information that students mostly likely have not seen even after finishing EGR1010 and that are typically found in advanced level engineering courses (beyond introductory courses). Courses in thermodynamics, advanced physics, or later calculus courses cover these advanced concepts.

These surveys were used for two fundamental purposes: First, students are expected to assign identical questions on the two surveys with a higher confidence in the post-course survey. Second, students are expected to rate their confidence similarly on questions of similar difficulty, relative to their stage in the curriculum. Questions from the first survey are identified with a subscript 1 followed by the unique question number. Post-survey questions are identified with a subscript 2 followed by the unique question number. For example, MED question 4 will be labeled MED14 in the pre-course survey and MED24 in the post-course survey.

Analysis points for Goals B and C:

1. Students will increase their confidence in answering identical questions.

2. Students will increase in their confidence in answering matched levels of questions. (ESY-MED, MED-HRD, HRD-ADV)

3. The Survey instruments will show that students perceive the questions by difficulty of question type.

4. The change in student confidence will further support the APCM findings from the Engage Survey.

\section{Testing the Pre-Course Survey}

In order to provide a minimal analysis of the survey to ascertain that the questions were at least measuring a similar subject matter factor analysis should be performed to determine the underlying variables of a survey. Factor analysis determines the minimum number of underlying variables in a data set by testing for a covariance of these variables. It is important to note that factor analysis does not assume that the magnitude of the variables are similar, just that these factors demonstrate covariance to the degree that they are aligned (Tucker, 1973). In this case the study assumes that the underlying variables are the question levels and the student responses 
would vary within each level. A factor analysis using Varimax Rotation of the first survey using a 3 factor assumption is shown below in Figure 1. Ideally students would accurately perceive three distinct difficulty levels. In reality students mostly assigned questions into 2 levels. In either case, the Cronback alpha values remained above .8 for all questions and correlation matrix revealed only slight correlations among items (Appendix C). ESY13 and MED16 were the only factors identified as being part of a third difficulty level. Figure 2 shows a factor analysis for the same responses using only 2 factors. ESY13 and MED16 are assimilated into the second factor in this analysis. The revised analysis in Figure 2 shows that two factors are sufficient for explaining the difference in student perception of the test question. While the expected three distinct factors did not emerge in the student responses, the students rated the difficulty of the ESY questions consistently, and grouped the MED and HRD questions into one level. This may be explained by the student's ability to perceive differences in the question types based on their experience. ESY questions were prerequisite to the EGR1010 content. The other two types (MED and HRD) were not yet seen by many of the students and their difficulty was therefore perceived in the same way by the students.

\begin{tabular}{|l|r|r|r|r|r|r|}
\hline & Factor Loading \\
\hline & Factor 1 & Factor 2 & Factor 3 & & & \\
\hline
\end{tabular}

In the three factor model, MED16 and ESY13 are separated and significant. For future iterations of the survey, it will be necessary to review the content of these two questions. 
Examining their similarities to each other and differences from the other questions of the same level should lead to an understanding of what caused the different student perception.

\section{Testing the Post-Course Survey}

Similar to the pre-course survey, the post-course survey results were analyzed using factor analysis. As with the pre-course survey, the Cronback alpha values remained above 8 for all questions and correlation matrix revealed only slight correlations among items (Appendix D). In this post-course survey analysis, there was more obvious alignment in two factors. MED and HRD factors were grouped together in student perceptions and ADV questions formed a second factor. This is in contrast to the pre-course survey, where ESY questions were separate. In the post-course survey, all MED questions were grouped with most of the HRD questions. The results for two HRD questions were ambiguous with no significant alignment to one or the other factor.

\begin{tabular}{|c|c|c|c|c|c|c|}
\hline \multicolumn{4}{|c|}{$\begin{array}{c}\text { Maximum Likelihood / Varimax Rotated } \\
\text { Factor Loading }\end{array}$} & \multicolumn{3}{|c|}{$\begin{array}{c}\text { Maximum Likelihood / Varimax Rotated } \\
\text { Factor Loading }\end{array}$} \\
\hline & Factor 1 & Factor 2 & Factor 3 & & Factor 1 & Factor 2 \\
\hline MED21 & 0.834 & 0.171 & -0.013 & MED21 & 0.830 & 0.180 \\
\hline MED23 & 0.795 & 0.324 & 0.064 & MED22 & 0.688 & 0.394 \\
\hline MED22 & 0.692 & 0.387 & -0.127 & MED23 & 0.797 & 0.331 \\
\hline MED24 & 0.893 & 0.179 & -0.151 & MED24 & 0.880 & 0.192 \\
\hline MED25 & 0.842 & 0.280 & 0.277 & MED25 & 0.838 & 0.288 \\
\hline MED26 & 0.905 & 0.166 & 0.135 & MED26 & 0.903 & 0.175 \\
\hline HRD23 & 0.642 & 0.446 & -0.166 & HRD23 & 0.632 & 0.448 \\
\hline HRD25 & 0.751 & 0.347 & 0.083 & HRD25 & 0.756 & 0.352 \\
\hline HRD26 & 0.792 & 0.313 & -0.081 & HRD26 & 0.788 & 0.319 \\
\hline ADV24 & 0.683 & 0.483 & -0.064 & ADV24 & 0.677 & 0.492 \\
\hline HRD24 & 0.255 & 0.758 & -0.145 & HRD24 & 0.245 & 0.755 \\
\hline ADV21 & 0.389 & 0.579 & -0.102 & ADV21 & 0.379 & 0.587 \\
\hline ADV22 & 0.013 & 0.782 & 0.118 & ADV22 & 0.011 & 0.782 \\
\hline ADV23 & 0.319 & 0.729 & 0.123 & ADV23 & 0.317 & 0.729 \\
\hline ADV25 & 0.345 & 0.669 & 0.325 & ADV25 & 0.352 & 0.652 \\
\hline ADV26 & 0.349 & 0.715 & -0.115 & ADV26 & 0.339 & 0.719 \\
\hline HRD22 & 0.503 & 0.514 & -0.139 & HRD22 & 0.492 & 0.522 \\
\hline HRD21 & 0.589 & 0.413 & 0.102 & HRD21 & 0.588 & 0.417 \\
\hline \multicolumn{4}{|c|}{$\begin{array}{l}\text { Figure } 3 \text { Factor analysis assuming } 3 \\
\text { factors for Post-Course survey }\end{array}$} & \multicolumn{3}{|c|}{$\begin{array}{l}\text { Figure } 4 \text { Factor Analysis assuming } 2 \\
\text { factors for Post-Course survey }\end{array}$} \\
\hline
\end{tabular}

As with the pre survey, the alignment of factors may be due to student perception. The students may see MED and HRD questions as easier after taking EGR1010. Alternatively, it may be that the ADV questions are just more difficult. Further study into the exact meaning behind the 
student answers is necessary to more precisely understand student perceptions. The observed grouping of questions roughly into the expected groups for similar question level is encouraging.

Next, regression analysis was utilized to analyze these components more globally, rather than question by question, in order to ascertain if the overall value of question level corresponds to difference in average score. This type of one dimensional analysis is the hallmark of this type of research and may be where many studies conclude. While this analysis yields a strong indication that the students see the question types as different across the pre-course and postcourse tests, this study will endeavor to include the full range of two dimensional analysis to provide deeper analysis into the findings. Figure 5 shows results of a comparison of mean confidence levels for the four question levels given on the pre and post-course surveys. It is consistent with the design of the survey that the students rated easy questions highest (most confidence) to advanced questions lowest (least confidence). While MED and HRD questions were used in both surveys, it is important to take a step back and evaluate the data collectively to ascertain if ESY, MED/HRD, and ADV are scored in some order of expected value. Further specification of pre and post analysis is discussed later and shown in Figure 8 to provide further explanatory value with respect to time.

\begin{tabular}{|c|c|c|c|c|c|}
\hline \multicolumn{6}{|c|}{ LSMeans Differences Student's t } \\
\hline \multicolumn{2}{|c|}{$\alpha=0.050 \mathrm{t}=1.96055$} & & & & \\
\hline Level & & & & & $\begin{array}{r}\text { Least Sq } \\
\text { Mean }\end{array}$ \\
\hline ESY & A & & & & 4.570852 \\
\hline MED & & B & & & 3.3782933 \\
\hline HRD & & & $\mathrm{C}$ & & 3.1739049 \\
\hline ADV & & & & $\mathrm{D}$ & 2.9297997 \\
\hline
\end{tabular}

Levels not connected by same letter are significantly different

\section{Figure 5 Comparison test of Pre and Post survey question levels}

Overall, the analyses of the pre and post-test support its use as a method for measuring the change in efficacy. The designed question levels are perceived by students to be significantly different. Therefore changes in student scoring between the pre- and post-survey should provide insight into the effect of EGR1010 on student efficacy in relation to mathematics.

\section{Efficacy Survey Findings}

Regression analysis was used to determine how the student responses to the survey were associated with the following coding used for categorical variables: timing pre (1) or post (2), level of question (ESY, MED, HRD, ADV), and APCM group of each student. In the results that follow, the four APCM Groups when separated are coded A (Achievers), S (Support Seekers), P (Purpose Seekers) and P\&S (Purpose \& Support Seekers). The overall JMP analysis is shown in Figure 6. It is important to note that previous iterations of the regression utilized a full factorial method and generated biased results and very weak correlations for all but the twodimensional and single variables shown below. The results below were achieved after reducing 
the regressed variables by eliminating the three-dimensional analysis and the cross of timing and level. Neither of these two analyses provided explanatory value.

\begin{tabular}{|l|r|r|r|r|r|}
\hline Summary of Fit & & & \\
\hline RSquare & 0.167 & & & \\
\hline RSquare Adj & 0.163 & & & \\
\hline Root Mean Square Error & 1.259 & & & \\
\hline Mean of Response & 3.508 & & & \\
\hline Observations (or Sum Wgts) & 4104 & & & \\
\hline Analysis of Variance & & & & \\
\hline & & Sum of & Mean & \\
\hline Source & DF & Squares & Square & F Ratio & \\
\hline Model & 19 & 1293.668 & 68.0878 & 42.9515 & \\
\hline Error & 4084 & 6474.067 & 1.585 & Prob $>$ F & \\
\hline C. Total & 4103 & 7767.735 & & $<.0001 *$ & \\
\hline Effect Tests & & & & & \\
\hline & & & Sum of & & \\
\hline Source & Nparm & DF & Squares & F Ratio & Prob > F \\
\hline APCM*level & 9 & 9 & 38.460 & 2.696 & $0.0040^{*}$ \\
\hline APCM & 3 & 3 & 56.745 & 11.932 & $<.0001^{*}$ \\
\hline timing (1 or 2) & 1 & 1 & 290.741 & 183.406 & $<.0001^{*}$ \\
\hline APCM*timing (1 or 2) & 3 & 3 & 32.514 & 6.837 & $0.0001^{*}$ \\
\hline level & 3 & 3 & 470.707 & 98.978 & $<.0001^{*}$ \\
\hline
\end{tabular}

\section{Figure 6 Results of regression analysis of student responses with independent variables, APCM group, question level, timing and their interactions}

The level of question, timing, APCM group and the interaction of APCM with level and timing were all significant. This is strong evidence that the average student's confidence reported for each question level was different, consistent with Figure 6. These results also indicate that the reported confidence level depends on the timing of the question. This supports the hypothesis that there is a change in how students perceive the difficulty of similar questions due to taking EGR1010. Also significant was that the APCM group of each student affected their scoring. The significance of the interaction of APCM with both timing and level indicate a more complicated relationship linking the effect of EGR1010 on the perceptions within different APCM groups. detail.

Figure 7 studies the relationship between APCM group and question timing in more 


\begin{tabular}{|c|c|c|c|c|c|}
\hline \multicolumn{6}{|c|}{ APCM $*$ timing $(1$ or 2$)$} \\
\hline \multicolumn{6}{|c|}{ LSMeans Differences Student's t } \\
\hline \multicolumn{2}{|c|}{$\alpha=0.050 \mathrm{t}=1.961$} & & & & \\
\hline Level & & & & & $\begin{array}{r}\text { Least Sq } \\
\text { Mean }\end{array}$ \\
\hline A,2 & A & & & & 4.166 \\
\hline $\mathrm{S}, 2$ & A & & & & 4.151 \\
\hline PandS,2 & & $\mathrm{B}$ & & & 3.785 \\
\hline $\mathrm{P}, 2$ & & B & & & 3.701 \\
\hline PandS,1 & & & $\mathrm{C}$ & & 3.377 \\
\hline $\mathrm{A}, 1$ & & & $\mathrm{C}$ & & 3.166 \\
\hline $\mathrm{P}, 1$ & & & & $\mathrm{D}$ & 2.930 \\
\hline$S, 1$ & & & & $\mathrm{D}$ & 2.830 \\
\hline
\end{tabular}

Levels not connected by same letter are significantly different.

\section{Figure 7 LS means Student's t for APCM type and survey question timing}

The following conclusions can be drawn from the values observed in Figure 7:

1. Achievers assigned the highest confidence in both the pre-course and the post-course survey, statistically tying in the pre-survey. Surprisingly, the Purpose and Support Seeker's confidence in the pre-course survey could not be distinguished from the Achievers confidence in the same survey. Other research has reported that students in this group may have abnormally high regard for their ability (Kamarraju, 2013)

2. Support Seekers reported the lowest confidence of any group (2.83) in the pre-course survey. In the post-course survey this group reported the second highest confidence, which was not distinguishable from the Achievers on the post-course survey. This change of 1.32 points is by far the most of any group between the surveys. This supports the very strong overall effect that EGR1010 has on the Support Seekers. This confirms one of this study's main hypotheses that Support Seekers gain the most from the curriculum of EGR1010 because of the improvement in Efficacy they receive from the course. The increase most likely accounts for the continued success they have through to graduation. 


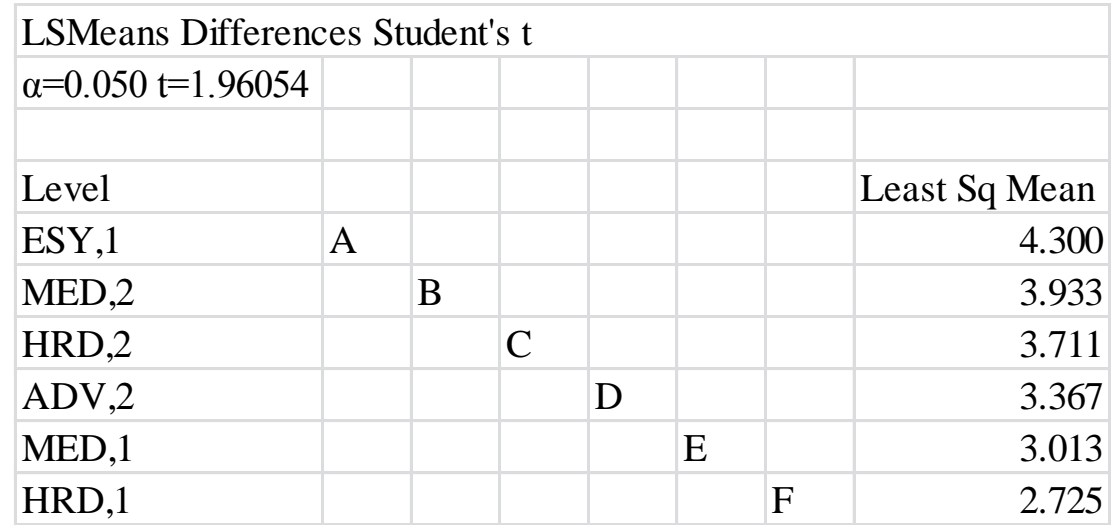

Levels not connected by same letter are significantly different.

\section{Figure $8 \mathrm{LS}$ means Student's t for interaction of question level and timing}

Figure 8 shows the analysis of the interaction of question level and timing. This figure further explores the findings in Figure 7 that show a significant difference between question levels.

The following observations are evident from Figure 8:

1. The easy questions from the first survey were scored with the highest confidence of any question.

2. The ordering of student confidence is consistent with the designed question difficulty within each of the pre-course survey and post-course results. The easier questions within each survey were rated with higher confidence.

3. Confirmation of the hypothesis that students would score similar questions to be less difficult after taking the class compared to before. In comparison of identical questions, (MED, 1 versus MED, 2) and (HRD, 1 versus HRD, 2), responses from the post-course survey were significantly higher than their pre-course survey counterparts.

4. The ADV questions in the post-course survey were scored significantly higher than the MED and HRD questions from the first survey. Overall, students felt more confident in their ability to solve problems after the course. This confidence extended to the more advanced engineering problems found in the ADV examples, which were well beyond the topics covered in EGR1010.

Figure 9 details the analysis of the interaction between the level of the question and the APCM group, for further dissection of data additional criteria of including the first and second survey is included in Appendix E. The following observations are evident:

1. The confidence reported by Purpose and Support Seekers for the MED, HRD and ADV scores are concentrated and not significantly different. It appears that many of the students saw no difference between the questions. This may imply that the questions were perceived as universally hard. Alternatively, it is possible that they simply answered identically throughout the survey (3 for every answer). In support of the former interpretation, the confidence reported by Purpose and Support Seekers 
on the ESY questions is significantly higher. It is most likely that Purpose and Support Seekers saw the non-ESY questions as being equally difficult and indistinguishable, while still considering each question's difficulty separately.

2. Purpose seekers' reported confidence was not significantly different between the MED and HRD questions. Purpose Seekers scored ADV questions with the lowest confidence among the four question types, but the difference between reported confidence on ADV and MED questions for this group was not significant.

3. The Support Seekers' reported confidence on the different level of questions was consistent with expectations, i.e. they scored easier questions with a higher confidence.

4. The confidence reported by Achievers, Purpose Seekers, and Support Seekers on the ADV questions could not be distinguished from each other. All three groups reported very low confidence on these questions.

\begin{tabular}{|c|c|c|c|c|c|c|c|c|c|}
\hline \multicolumn{10}{|c|}{ LSMeans Differences Student's t } \\
\hline \multicolumn{9}{|c|}{$\alpha=0.050 \mathrm{t}=1.961$} & \multirow[b]{2}{*}{$\begin{array}{r}\text { Least Sq } \\
\text { Mean }\end{array}$} \\
\hline Level & & & & & & & & & \\
\hline A,ESY & A & & & & & & & & 4.942 \\
\hline S,ESY & A & & & & & & & & 4.814 \\
\hline $\mathrm{P}, \mathrm{ESY}$ & & B & & & & & & & 4.323 \\
\hline PandS,ESY & & B & & & & & & & 4.204 \\
\hline A,MED & & & $\mathrm{C}$ & & & & & & 3.563 \\
\hline S,MED & & & $\mathrm{C}$ & $\mathrm{D}$ & & & & & 3.410 \\
\hline PandS,ADV & & & $\mathrm{C}$ & $\mathrm{D}$ & $\mathrm{E}$ & & & & 3.396 \\
\hline PandS,MED & & & $\mathrm{C}$ & $\mathrm{D}$ & E & & & & 3.383 \\
\hline PandS,HRD & & & $\mathrm{C}$ & $\mathrm{D}$ & $\mathrm{E}$ & & & & 3.342 \\
\hline A,HRD & & & & $\mathrm{D}$ & $\mathrm{E}$ & & & & 3.272 \\
\hline $\mathrm{P}, \mathrm{MED}$ & & & & $\mathrm{D}$ & $\mathrm{E}$ & $\mathrm{F}$ & & & 3.156 \\
\hline S,HRD & & & & & $\mathrm{E}$ & $\mathrm{F}$ & G & & 3.103 \\
\hline P,HRD & & & & & & $\mathrm{F}$ & G & $\mathrm{H}$ & 2.979 \\
\hline $\mathrm{A}, \mathrm{ADV}$ & & & & & & & G & $\mathrm{H}$ & 2.887 \\
\hline $\mathrm{P}, \mathrm{ADV}$ & & & & & & & G & $\mathrm{H}$ & 2.802 \\
\hline S,ADV & & & & & & & & $\mathrm{H}$ & 2.635 \\
\hline
\end{tabular}

Levels not connected by same letter are significantly different

\section{Figure 9 LS means differences Student's t for APCM group and question level}

\section{Conclusion and Discussion}

The study demonstrates the ability to measure changes in mathematics self-efficacy over the course of one semester in which students took a mathematics intervention course. Further analysis of the survey tool shows that it provides a high level of reliability and that it may be used to further demonstrate understanding about the impacts of a mathematics intervention.

The study also shows that students' efficacy improved while taking EGR1010, supporting the APCM framework. Each student group in the APCM perceived mathematics questions before and after the course differently. Students felt they would do better on future mathematics 
work after the course as evidenced by their change in view of the MED and HRD questions from survey 1 to survey 2; this also supported the APCM framework which meets the goals of this study.

Overall, students showed an increase in their perceived ability to answer mathematics questions after taking EGR1010. This increase was strongest in the Support Seekers group. This is the same group that had the highest increase in graduation rates in the longitudinal study. A multi-dimensional study of the level and timing of questions support the theory that APCM provides a framework for effectively describing and assessing the student population in open enrollment schools like the one in this study.

The survey should be reviewed for possible improvements. Determining the full issue in relation to students seeing MED and HRD questions similarly will help identify if changes need to be made. With this in mind, the survey was not designed or tested to provide an absolute measure of efficacy, and yet the survey was able to serve its purpose in identifying a change in student perception of their ability to answer mathematics questions. The survey may, however, be used as an absolute measure of student efficacy in mathematics with further study. To do this, the survey should be more fully vetted for accuracy and precision. Further understanding of the numeric values from the survey in terms of defining efficacy would be useful, including a potential one-to-one mapping of a survey result to an absolute efficacy scale.

Further analysis should be done with regards to the ability of this survey structure to be applied to other measurements. Additionally, the survey questions may be modified to provide greater separation between question levels. This change could provide greater understanding of student perceptions with specific question levels and difficulties.

Future studies may include measuring the decrease in efficacy that is presumed to occur in mathematics specific courses leading to student attrition, or in courses at different levels of academic experience. 


\section{Appendix A - Pre-Course Revised Efficacy Survey}

\section{Mathematics Problems}

Please indicate how much confidence you have that you could successfully solve each of these problems if exposed to the course material by circling the number according to the following 5-point confidence scale.

Confidence Scale:

No Confidence

1

2

3

Total Confidence

\begin{tabular}{|c|c|}
\hline 1. Solve the equation $2 x^{2}+6 x+7=3$ & $\begin{array}{lllll}1 & 2 & 3 & 4 & 5\end{array}$ \\
\hline 2. If $V_{L}=100 / I ; V_{R}=20 I ;$ and $120=V_{L}+V_{R} ;$ solve for current I & $\begin{array}{lllll}1 & 2 & 3 & 4 & 5\end{array}$ \\
\hline $\begin{array}{l}\text { 3. Compute the indefinite integral: } \\
\qquad \int \frac{e^{x} d x}{\sqrt{1-4 e^{2 x}}}\end{array}$ & $\begin{array}{lllll}1 & 2 & 3 & 4 & 5\end{array}$ \\
\hline $\begin{array}{l}\text { 4. Find the area of a surface created by rotating the graph of } y=x^{3} \text { from } x= \\
0 \text { to } x=1 \text { about the } x \text {-axis. }\end{array}$ & $\begin{array}{lllll}1 & 2 & 3 & 4 & 5\end{array}$ \\
\hline 5. If given angle $\mathrm{A}$ and side $\mathrm{a}$, find the hypotenuse. & $\begin{array}{lllll}1 & 2 & 3 & 4 & 5\end{array}$ \\
\hline $\begin{array}{l}\text { 6. Find equivalent resistance for } 2 \text { resistors }\left(R_{1} \& R_{2}\right) \text { in parallel if } \\
R=R_{1} R_{2} / R_{1}+R_{2}\end{array}$ & $\begin{array}{lllll}1 & 2 & 3 & 4 & 5\end{array}$ \\
\hline $\begin{array}{l}\text { 7. If you walk an } 80^{\circ} \text { arc of the perimeter of a circle with radius of } 100 \text { feet } \\
\text { how many feet do you walk? }\end{array}$ & $\begin{array}{lllll}1 & 2 & 3 & 4 & 5\end{array}$ \\
\hline 8. Give the vector for: from $(1,-8,4)$ to $(1,2,-4)$ & $\begin{array}{lllll}1 & 2 & 3 & 4 & 5\end{array}$ \\
\hline
\end{tabular}




\begin{tabular}{|c|c|}
\hline $\begin{array}{l}\text { 9. If } V_{I}(t)=R C \frac{d V_{o}}{d t} \text { and } V_{I}(t)=12 \cos (100 t) \text { volts determine the output } \\
\text { voltage } V_{o}(t) \text { assuming initial voltage is zero. }\end{array}$ & $\begin{array}{lllll}1 & 2 & 3 & 4 & 5\end{array}$ \\
\hline $\begin{array}{l}\text { 10. A cooling fin with height } \mathrm{y} \text { and width } \mathrm{x} \text { is approximated by the equation } \\
y(x)=-\frac{1}{4}\left(x^{2}-36\right) \text {. Determine the height and width of the fin. }\end{array}$ & $\begin{array}{lllll}1 & 2 & 3 & 4 & 5\end{array}$ \\
\hline $\begin{array}{l}\text { 11. Determine the equation of a plane that contains the points: } P=(1,-1,3) \text {, } \\
Q=(2,3,4) \text { and } R=(0,-2,3)\end{array}$ & $\begin{array}{lllll}1 & 2 & 3 & 4 & 5\end{array}$ \\
\hline $\begin{array}{l}\text { 12. For the equation } h(t)=96 t-16 t^{2} \text {, find both values of } \mathrm{t} \text { for } \mathrm{h}=80 \mathrm{using} \\
\text { the quadratic formula. }\end{array}$ & $\begin{array}{lllll}1 & 2 & 3 & 4 & 5\end{array}$ \\
\hline $\begin{array}{l}\text { 13. Determine the center of mass for the region bounded by } y=2 x^{3} \text { and } y= \\
3 x\end{array}$ & $\begin{array}{lllll}1 & 2 & 3 & 4 & 5\end{array}$ \\
\hline $\begin{array}{l}\text { 14. For a pendulum with a force applied to it } f(t) \text {, and the angle from vertical } \\
\text { resulting from the force satisfies the equation } m l \ddot{\theta}+m g \theta=f(t) \text {, find the } \\
\text { steady state solution } \theta_{S S}(t) \text {. }\end{array}$ & $\begin{array}{lllll}1 & 2 & 3 & 4 & 5\end{array}$ \\
\hline $\begin{array}{l}\text { 15. If given velocities after } 1 \text { sec. and after } 3 \text { secs., and given } v(t)=v_{0}+a t \\
\text { find the initial velocity and acceleration of an object }\end{array}$ & $\begin{array}{lllll}1 & 2 & 3 & 4 & 5\end{array}$ \\
\hline 16. Sketch the graph for the conditions given in question 15 . & $\begin{array}{lllll}1 & 2 & 3 & 4 & 5\end{array}$ \\
\hline $\begin{array}{l}\text { 17. Given initial conditions: } R C \frac{d V(t)}{d t}+V(t)=3, V(0)=-7.0 \mathrm{~V} \text {; determine } \\
\text { the transient solution } V_{\text {trans }}(t) \text { for a circuit. }\end{array}$ & $\begin{array}{lllll}1 & 2 & 3 & 4 & 5\end{array}$ \\
\hline $\begin{array}{l}\text { 18. A car traveling at } 50 \mathrm{mph} \text { skids to a stop taking } 3.25 \text { seconds. What is the } \\
\text { skidding distance assuming acceleration is uniform? }\end{array}$ & $\begin{array}{lllll}1 & 2 & 3 & 4 & 5\end{array}$ \\
\hline
\end{tabular}




\section{Appendix B - Post-Course Revised Efficacy Survey}

\section{Mathematics Problems}

Please indicate how much confidence you have that you could successfully solve each of these problems if exposed to the course material by circling the number according to the following 5-point confidence scale.

Confidence Scale:

No Confidence 1

2

34

5

\begin{tabular}{|c|c|}
\hline $\begin{array}{l}\text { 1. A } 1.5 \mathrm{~kg} \text { rock released from rest at the surface of a calm lake. If the } \\
\text { resistance offered by the water as the rock falls is directly proportional to the } \\
\text { rocks velocity, the rocks acceleration is } \mathrm{a}=\mathrm{g}-\mathrm{Cd}(\mathrm{v} / \mathrm{m}) \text {, where } \mathrm{g} \text { is the } \\
\text { acceleration due to gravity, Cd is the constant } \mathrm{drag} \text { coefficient, } \mathrm{v} \text { is the rocks } \\
\text { velocity, and } \mathrm{m} \text { is the rocks mass. Letting } \mathrm{Cd}=4.1 \mathrm{~kg} / \mathrm{s} \text {, determine the rocks } \\
\text { velocity after } 1.8 \text { seconds. }\end{array}$ & $\begin{array}{lllll}1 & 2 & 3 & 4 & 5\end{array}$ \\
\hline 2. If $V_{L}=100 / I ; V_{R}=20 I ;$ and $120=V_{L}+V_{R} ;$ solve for current I & $\begin{array}{lllll}1 & 2 & 3 & 4 & 5\end{array}$ \\
\hline $\begin{array}{l}\text { 3. Compute the indefinite integral: } \\
\qquad \int \frac{e^{x} d x}{\sqrt{1-4 e^{2 x}}}\end{array}$ & $\begin{array}{lllll}1 & 2 & 3 & 4 & 5\end{array}$ \\
\hline $\begin{array}{l}\text { 4. Find the area of a surface created by rotating the graph of } y=x^{3} \text { from } x= \\
0 \text { to } x=1 \text { about the } x \text {-axis. }\end{array}$ & $\begin{array}{lllll}1 & 2 & 3 & 4 & 5\end{array}$ \\
\hline $\begin{array}{l}\text { 5. A plastic film moves over two drums. During a } 4 \mathrm{~s} \text { interval the speed of the } \\
\text { tape is increased uniformly from } \mathrm{v} 0=2 \mathrm{ft} / \mathrm{s} \text { to } \mathrm{v} 1=4 \mathrm{ft} / \mathrm{s} \text {. Knowing that the tape } \\
\text { does not slip on the drums, determine (a) the angular acceleration of drum } \mathrm{B} \text {, (b) } \\
\text { the number of revolutions executed by drum } \mathrm{B} \text { during the } 4 \mathrm{~s} \text { interval. }\end{array}$ & $\begin{array}{lllll}1 & 2 & 3 & 4 & 5\end{array}$ \\
\hline $\begin{array}{l}\text { 6. Find equivalent resistance for } 2 \text { resistors }\left(R_{1} \& R_{2}\right) \text { in parallel if } \\
R=R_{1} R_{2} / R_{1}+R_{2}\end{array}$ & $\begin{array}{lllll}1 & 2 & 3 & 4 & 5\end{array}$ \\
\hline $\begin{array}{l}\text { 7. Consider a linear time-invariant system such that } \\
\qquad H(e j \omega)=1(1-12 e j \omega) 2 \\
\text { If the input } \tilde{x}[\mathrm{n}] \text { is periodic with period } \mathrm{N}_{0}=8 \text {, then determine the output } \\
\text { Fourier series coefficient } \mathrm{y}_{4} \text { if } \mathrm{x}_{4}=9 .\end{array}$ & $\begin{array}{lllll}1 & 2 & 3 & 4 & 5\end{array}$ \\
\hline 8. Give the vector for: from $(1,-8,4)$ to $(1,2,-4)$ & $\begin{array}{lllll}1 & 2 & 3 & 4 & 5\end{array}$ \\
\hline $\begin{array}{l}\text { 9. If } V_{I}(t)=R C \frac{d V_{o}}{d t} \text { and } V_{I}(t)=12 \cos (100 t) \text { volts determine the output } \\
\text { voltage } V_{o}(t) \text { assuming initial voltage is zero. }\end{array}$ & $\begin{array}{lllll}1 & 2 & 3 & 4 & 5\end{array}$ \\
\hline
\end{tabular}




\begin{tabular}{|c|c|}
\hline $\begin{array}{l}\text { 10. A cooling fin with height } \mathrm{y} \text { and width } \mathrm{x} \text { is approximated by the equation } \\
y(x)=-\frac{1}{4}\left(x^{2}-36\right) \text {. Determine the height and width of the fin. }\end{array}$ & $\begin{array}{lllll}1 & 2 & 3 & 4 & 5\end{array}$ \\
\hline $\begin{array}{l}\text { 11. Determine the equation of a plane that contains the points: } P=(1,-1,3) \text {, } \\
\mathrm{Q}=(2,3,4) \text { and } \mathrm{R}=(0,-2,3)\end{array}$ & $\begin{array}{lllll}1 & 2 & 3 & 4 & 5\end{array}$ \\
\hline $\begin{array}{l}\text { 12. A continuous random variable } X \text { that can assume any value between } x=2 \\
\text { and } x=5 \text { has a density function given by } f(x)=K(1+x) \text {. Find } P[X<4] \text {. }\end{array}$ & $\begin{array}{lllll}1 & 2 & 3 & 4 & 5\end{array}$ \\
\hline $\begin{array}{l}\text { 13. Determine the center of mass for the region bounded by } y=2 x^{3} \text { and } y= \\
3 x\end{array}$ & $\begin{array}{lllll}1 & 2 & 3 & 4 & 5\end{array}$ \\
\hline $\begin{array}{l}\text { 14. For a pendulum with a force applied to it } f(t) \text {, and the angle from vertical } \\
\text { resulting from the force satisfies the equation } m l \ddot{\theta}+m g \theta=f(t) \text {, find the } \\
\text { steady state solution } \theta_{S S}(t) \text {. }\end{array}$ & $\begin{array}{lllll}1 & 2 & 3 & 4 & 5\end{array}$ \\
\hline $\begin{array}{l}\text { 15. A fast food chain finds that the average time customers have to wait for } \\
\text { service is } 45 \text { seconds. If the waiting time can be treated as an exponential } \\
\text { random variable, what is the probability that a customer will have to wait } \\
\text { more than } 5 \text { minutes given that already he waited for } 2 \text { minutes? }\end{array}$ & $\begin{array}{lllll}1 & 2 & 3 & 4 & 5\end{array}$ \\
\hline $\begin{array}{l}\text { 16. A } 3 / 4 \text { inch diameter structural steel rod is subjected to an axial force of } 1.5 \\
\text { kips. Determine the deflection of end B. }\end{array}$ & $\begin{array}{lllll}1 & 2 & 3 & 4 & 5\end{array}$ \\
\hline $\begin{array}{l}\text { 17. Given initial conditions: } R C \frac{d V(t)}{d t}+V(t)=3, V(0)=-7.0 \mathrm{~V} \text {; determine the } \\
\text { transient solution } V_{\text {trans }}(t) \text { for a circuit. }\end{array}$ & $\begin{array}{lllll}1 & 2 & 3 & 4 & 5\end{array}$ \\
\hline $\begin{array}{l}\text { 18. A car traveling at } 50 \mathrm{mph} \text { skids to a stop taking } 3.25 \text { seconds. What is the } \\
\text { skidding distance assuming acceleration is uniform? }\end{array}$ & $\begin{array}{lllll}1 & 2 & 3 & 4 & 5\end{array}$ \\
\hline
\end{tabular}




\section{Appendix C - Correlation and Cronbach Alfa - Pre-Course Survey}

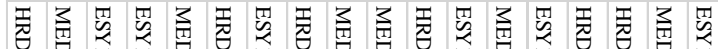

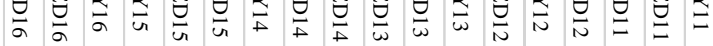

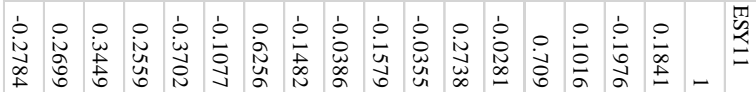

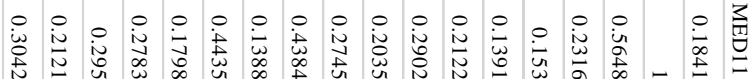
o

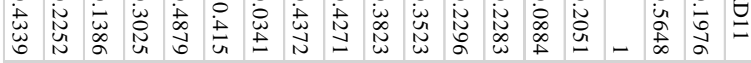

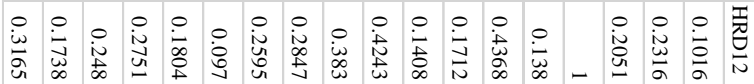

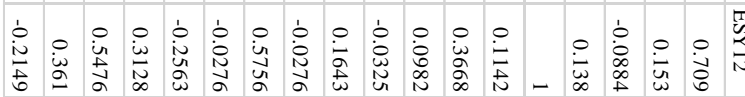

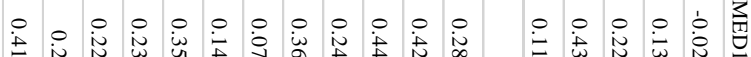

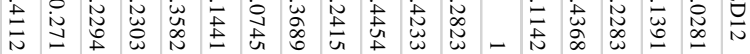

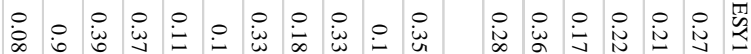

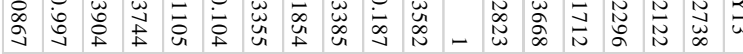

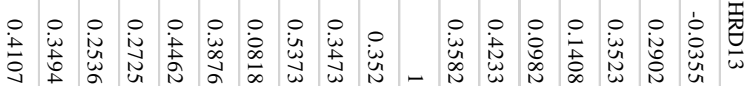

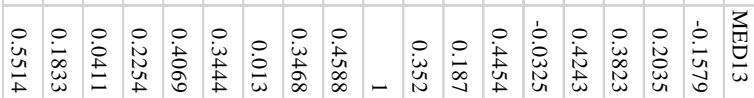

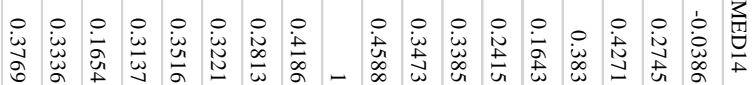

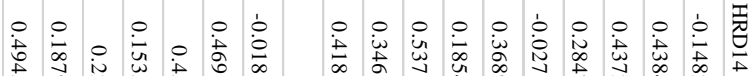

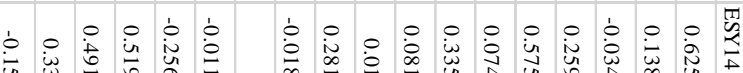

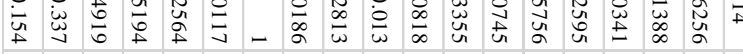

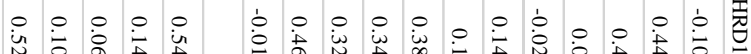

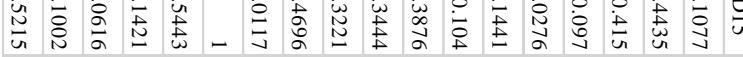

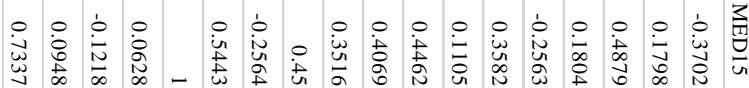

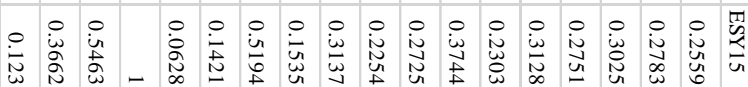

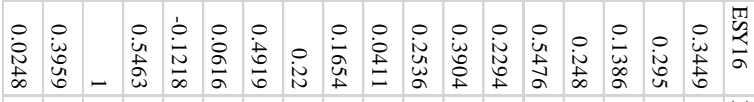

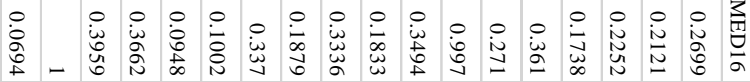

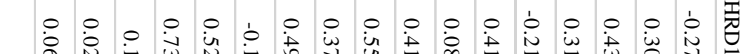

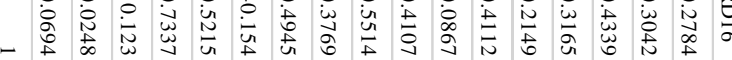

\begin{tabular}{|l|r|}
\hline \multicolumn{2}{|c|}{$\alpha$} \\
\hline ESY11 & 0.864 \\
\hline MED11 & 0.8519 \\
\hline HRD11 & 0.8506 \\
\hline HRD12 & 0.8544 \\
\hline ESY12 & 0.8601 \\
\hline MED12 & 0.8522 \\
\hline ESY13 & 0.8503 \\
\hline HRD13 & 0.8481 \\
\hline MED13 & 0.8512 \\
\hline MED14 & 0.848 \\
\hline HRD14 & 0.8489 \\
\hline ESY14 & 0.8593 \\
\hline HRD15 & 0.854 \\
\hline MED15 & 0.8548 \\
\hline ESY15 & 0.8519 \\
\hline ESY16 & 0.8547 \\
\hline MED16 & 0.8507 \\
\hline HRD16 & 0.8515 \\
\hline
\end{tabular}


Appendix D - Correlation and Cronbach Alfa - Post-Course Survey

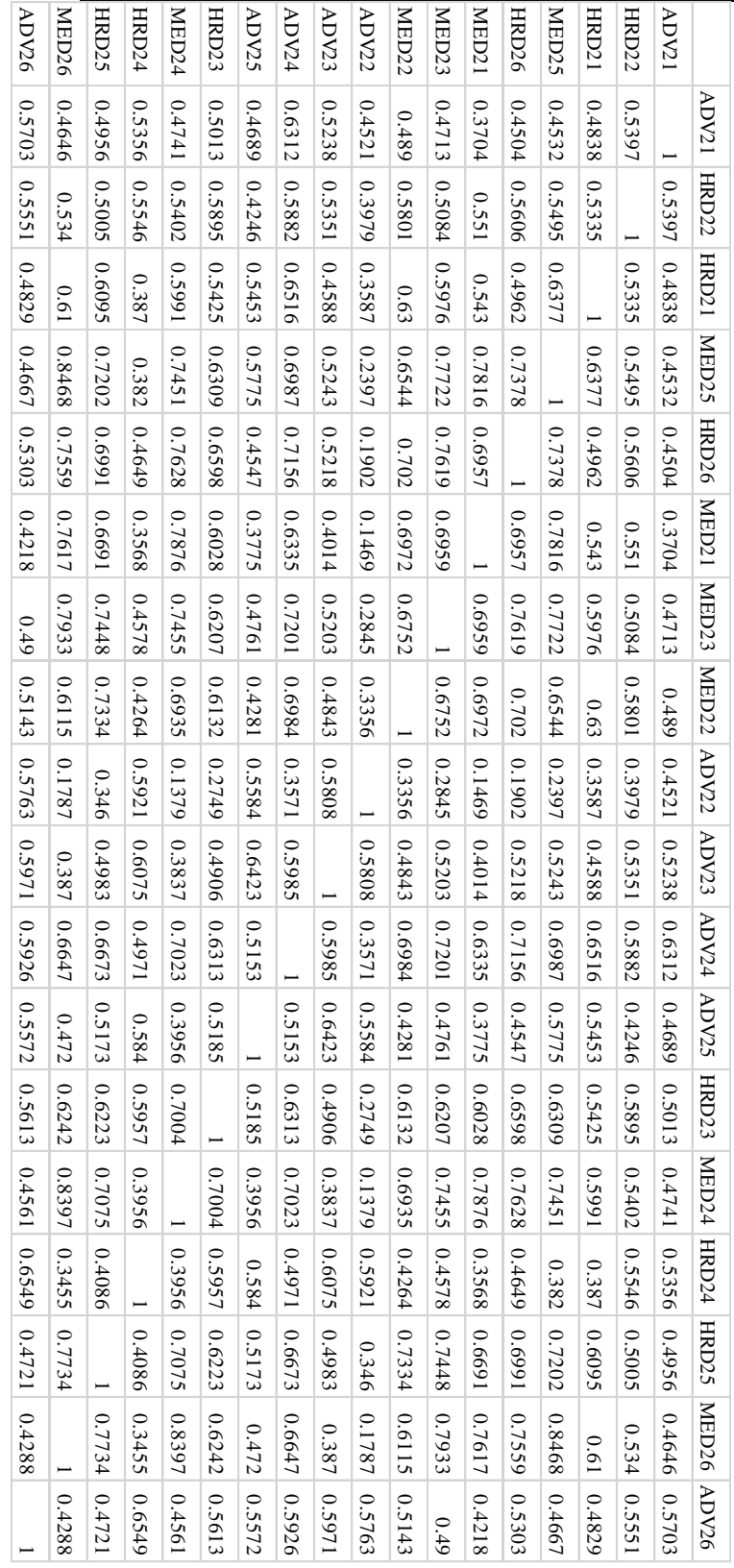

\begin{tabular}{|l|l|}
\hline & $\alpha$ \\
\hline ADV21 & 0.9553 \\
\hline HRD22 & 0.9544 \\
\hline HRD21 & 0.9542 \\
\hline MED25 & 0.9524 \\
\hline HRD26 & 0.9528 \\
\hline MED21 & 0.9537 \\
\hline MED23 & 0.9527 \\
\hline MED22 & 0.9531 \\
\hline ADV22 & 0.9581 \\
\hline ADV23 & 0.9547 \\
\hline ADV24 & 0.9524 \\
\hline ADV25 & 0.9551 \\
\hline HRD23 & 0.9533 \\
\hline MED24 & 0.9529 \\
\hline HRD24 & 0.9554 \\
\hline HRD25 & 0.9528 \\
\hline MED26 & 0.9528 \\
\hline ADV26 & 0.9545 \\
\hline
\end{tabular}

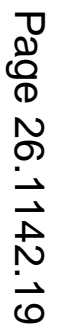




\section{References}

Barker, F.J. (2010). The effects of an engineering-mathematics course on freshmen students' mathematics selfefficacy. (unpublished master's thesis). Washington State University, Pullman, WA.

Bourne, A.L., Ciarallo, F.W., Klingbeil, N.W. (2014). Developing the Academic Performance-Commitment Matrix: How measures of objective academic performance can do more than predict college success. Proceedings $121^{\text {st }}$ ASEE Annual Conference and Exposition, Indianapolis, IN, June 2014.

Burnham, J.R. (2011). A case study of mathematics self-efficacy in a freshman engineering mathematics course. (unpublished master's thesis). Washington State University, Pullman, WA.

Klingbeil, N.W., Bourne, A.L. (2012). The Wright State Model for Engineering Mathematics Education: A Longitudinal Study of Program Impacts. Proceedings 2012 FYEE Conference, Pittsburgh, PA, August 2012.

Komarraju, M., Ramsey, A., Rinella, V. (2013). Cognitive and non-cognitive predictors of college readiness and performance: role of academic discipline. Learning and Individual Differences. 24, 103-109.

Lent, R. W., Lopez, F. G., , \& Bieschke, K. J. (1991). Mathematics Self-Efficacy. Journal of Counseling Psychology, 38(4), 424-430.

Lent, R.W., Sheu, H., Singley, D., Schmidt, J.A., Schmidt, L.C., Gloster, C.S. (2008). Longitudinal relations of selfefficacy to outcome expectations, interests, and major choice goals in engineering students. Journal of Vocational Behavior, 73, 328-335.

Tucker, L.R., Lewis, C. (1973) A reliability coefficient for maximum likelihood factor analysis. Psychometrika, 38(1), 1-10. 